\title{
ESOPHAGEAL REPLACEMENT IN CHILDREN
}

\section{Giannotti G., Garzi A., Pavone M., Ferrara F., Meucci D., Messina M.}

\author{
Division of Pediatric Surgery, Department of Pediatrics, Obstetrics and Reproductive Medicine \\ University Of Siena
}

Introduction: esophageal replacement in childhood, is indicated for intractable stenosis and long-gap atresia. When it is impossible to preserve the native esophagus we must create an appropriate conduit that should allow physiological oral feeding. Patients and Methods: we present two cases. The first patient, born with long gap esophageal atresia (AE), was submitted to ligation of fistula, gastrostomy and esophagostomy. When he was 1 years old came to our observation with two derivations. The radiological examination with contrast confirmed the large gap between the two oesophageal stumps. We decided to refer the patient to esophageal substitution with isoperistaltic jejunum through the posterior mediastinum. The second patient was born with AE type III and he was submitted to ligation of fistula, primary anastomosis, and 4 additional interventions of closure of recurrent fistula, esophageal resection and anti-reflux surgery. He came to our observation when he was 6 years old. The radiography showed esophageal dysmotility and dislocation of the stomach in the chest. We decided to subject the patient to esophageal replacement with stomach in toto. Results: Both patients had a good post-operative course. They began food orally in the first case in 18th day and in the second case in 7th. At follow-up after 1 year the children ate regularly, they don't show respiratory symptoms or gastro-oesophageal reflux and they have a good growth. Conclusions: Esophageal replacement is a complex surgical procedure, which provides various options. Only a careful preoperative evaluation allows us a choice of organ to be used as esophageal substitute. The colon is the most widely used. There are other surgical options that may offer, in skilled hands, the same guarantees. Both our cases have a good long term follow-up with regular diet and weight-height growth. Our experience confirms the validity of the 2 techniques, which include preferably the use of posterior mediastinal way and careful surgical preparation of the bowels.

Key words: esophageal atresia, esophageal replacement, quality of life.

\section{INTRODUCTION}

The ideal esophageal substitute should function as far as possible to the original structure. The patient should be able to swallow normally and should not experience any reflux and respiratory symptoms. An additional requisite in children is that the substitute should continue functioning for many years.(1) The most important indications for such reconstruction are long-gap esophageal atresia, caustic burn and occasionally peptic stricture. $(2 ; 3)$

The first reported oesophageal reconstruction in adult was in 1877 by Czerny. (4) Paediatric skin tube oesophageal replacement was performed in stages by Ladd and Gross to bridge the long gap in a patient with oesophageal atresia. (5) This tecnique became soon obsolete. Various oesophageal replacements were used, including jejunum by Roux in 1907 (6), a gastric tube by Gavriliu (7) and a gastric pull-up to replace the entire oesophagus by Sweet in 1947. (8) Colon replacement in children was first used by Dale in 1955. (9)

The present report describes the management and the outcome in two cases. One patient underwent esophageal replacement with isoperistaltic jejunum and another one with stomach in toto.

\section{CASE REPORT 1}

One year old boy was admitted in our Department. He was born with vaginal delivery at 40 gestational weeks and the pregnancy was normally. The infant was nursed on the
Neonatal Intensive Care Unit, because he had respiratory neonatal distress. Here it was diagnosed long-gap esophageal atresia and distal tracheo-esophageal fistula. Cervical oesophagostomy, gastrostomy and tracheo-esophageal fistula repair were performed when he was 1 week old. When he was admitted in our clinic, one year old, he had esophageal and gastric stomas and he fed via the gastrostomy just with liquid meal, for example milk. When he arrived at our department his weight was $5.500 \mathrm{~kg}$ and his height was 68,5 $\mathrm{cm}$. Weight and height percentile were lower than III percentile. Severe growth retardation was associated with slight mental retardation. The physical examination showed expired phisical condition, ligamentous laxity, plant hair and auricle down, absent tooth eruption and plant thumb proximal. Genetic counselling was performed to complete the general framework. A complete work-up was performed because a complex malformation syndrome was suspected. It included blood tests, karyotype analysis and diagnostic tests to discover congenital cardiac or kidney defects, that usually are associated with esophageal atresia. Genetic testing, cardiac and kidney function were normal. Routine blood tests, growth and thyroid levels were normal, except for anemia. Chest x-ray was performed and it was normal. The patient underwent examination by standard esophagograms with an iodised contrast. It highlighted esophagostomy and a normal transit in the esophageal upper pouch. Gastric and intestinal canalization were visualized by the contrast injected

Correspondence to:

Prof. Mario Messina, Division of Pediatric Surgery, Dept of Pediatrics, Obstetrics and Reproductive Medicine.

University of Siena. Policlinico "Le Scotte" - Viale Bracci - 53100 - Siena - Italy

Telefono: +39577586501 - Fax: +39577586174

E-mail: messinam@unisi.it 
through gastrostomy. In the preoperative period bronchoscopy was carried out to assess the presence of severe tracheomalacia because it's usually associated with oesophageal atresia. This exam showed a conventional tracheoscopic view of TM with reduction of the diameter of the posterior tracheal wall (in the middle third) and collapse (about $1,5 \mathrm{~cm}$ ) of anterior wall in the right part. There was also an important inflammation in the posterior tracheal wall. Tests carried out confirmed the presence of long-gap between the proximal and distal oesophagus, so oesophageal replacement was the only possible treatment. Isoperistaltic jejunal interposition was performed to replace the oesophagus in this case. (Figure 1) Two anastomosis were performed, one between the oesophageal cervical stump and the pedicle jejunal, the other between the jejunum and the anterior wall of the stomach. The patient had severe respiratory distress syndrome requiring ventilatory support, due to an extubation failure, so he was admitted to the Intensive care Unit for 17 days. On the 15 th postoperative day the patient was extubated, on the 18th day was discharged from the Intensive Care Unit and he was accepted in our department. During hospitalization in Intensive Care, he was fed by total parenteral nutrition via a central venous catheter that was inserted during the operation. On the 18th post-operative day, it was decided to start oral feeding, because the patient didn't have any respiratory problems. The patient was weaned from parenteral nutrition (PN) with mixed feeding and then he had an oral feeding. Logopedic rehabilitation was very important during the first days, because the child learnt to appreciate the food and to have a relationship with it; besides he knew and memorized swallowing function. Digestive $\mathrm{x}$-ray, performed one month after the operation, showed a fistula between the neo oesophagus and the overlying skin, where there was the old oesophagostomy. Another x-ray, two months ago, showed the fistula there wasn't. Now, about eighteen months after the operation, digestive x-ray shows a normal transit through neo oesophagus; there is neither anastomotic stricture nor anastomotic leak. The patient eats normally and he has got a good growth. He doesn't take any drugs and he doesn't have gastro-oesophageal reflux or respiratory disease. (Figure 2)

\section{CASE REPORT 2}

The second case report is about a child, with long-gap oesophageal atresia, who was admitted in our Department when he was 6 years old. The anamnesis showed that the child, at the birth, underwent, in another hospital, the operative correction of the oesophageal atresia, that consisted of ligation of the tracheooesophageal fistula and primary anastomosis of the oesophagus. He underwent other three operation to repair recurrent tracheo-oesophageal fistula, it was performed an esophageal resection due to an stricture where there was the old anastomosis and it was performed the gastrostomy. Finally the patient underwent an Dor fundoplication with removal of gastrostomy, about one year before admission in our Clinic. When he arrived at our department the child fed with liquid food or semiliquid food, weighed about $15200 \mathrm{~g}$ and he had recurrent bronchopneumonia. Routine blood tests, hormone levels and infection markers were normal, except a mild anemia. It was performed a x-ray of proximal digestive showing the oesophageal stricture in the middle third of upper oesophageal pouch with modest expansion upstream. It showed also an important hiatal hernia, with transhiatal migration and herniation of gastric fundic in the chest and gastro-esophageal reflux. (Figure 3) The dynamic exam showed the absence of peristaltic reflex with slow transit. Digestive endoscopy confirmed the gastroesophageal junction in the anomalous position about $6 \mathrm{~cm}$ above the esophageal iatus and the presence of confluent erosions (peptic oesophagitis of grade B based on the Los Angeles classification) in the esophageal mucosa due to an important reflux. The stricture, known in the past, was partial and the instrument could overcome the obstacle. Due to the brevity and the absence of peristaltic reflex it was decided to perform the oesophageal replacement in the child, with gastric transposition after pyloroplasty. The patient was nursed on the intensive care unit for a small period and on 2 nd postoperative day he was admitted to our Department. Based on the clinical regular course, on the 7th postoperative day, liquid oral feeding was started and all foods were reintegrated gradually. At the moment, one year after the operation, the child doesn't take any drugs, doesn't have any symptoms and he has got a good growth.

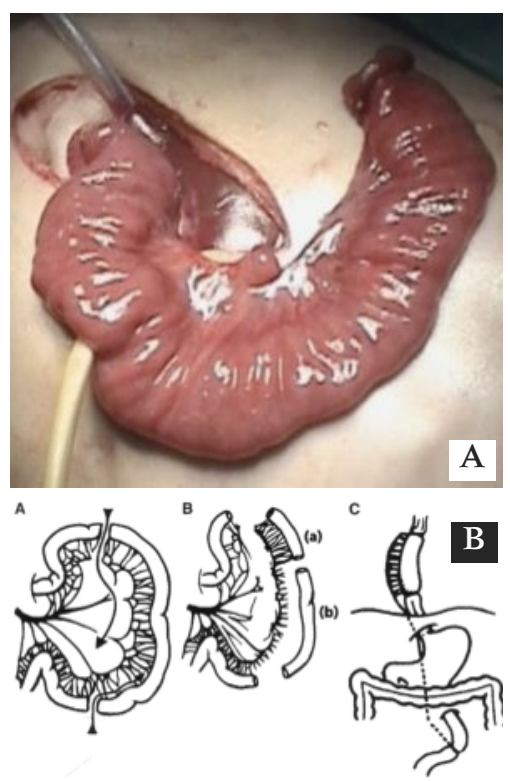

Fig.1: Esophageal replacement with isoperistaltic jejunum through posterior mediastinal route.

A: intraoperative image. B: design.

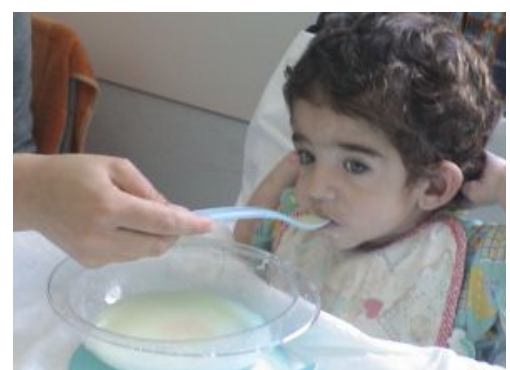

Fig.2: At 1 month post-surgery the child eat regularly. He has no respiratory symptoms or gastro-esophageal reflux and he has a good growth.

Fig.3: Preoperative rx proximal digestive that shows esophageal dysmotility and dislocation of the gastric fundus into the thorax.

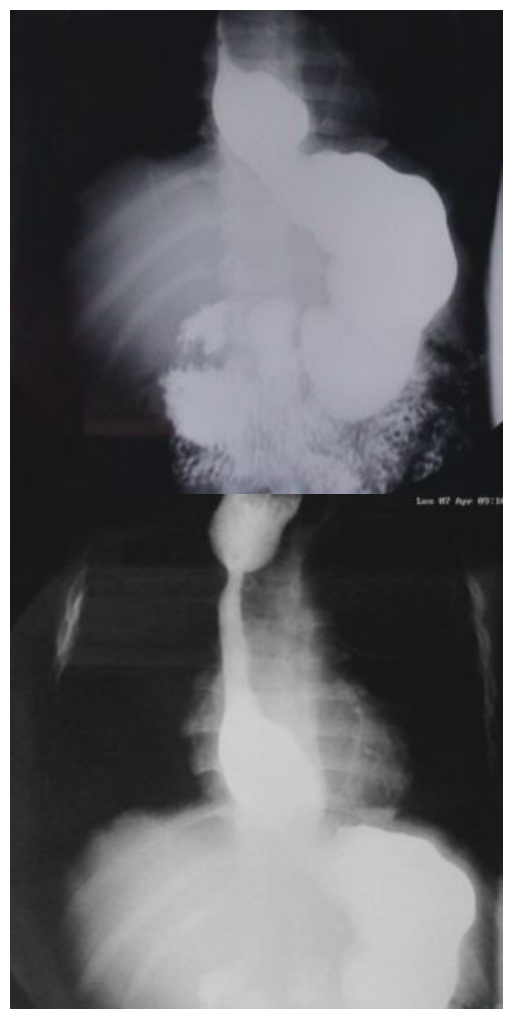




\section{DISCUSSION}

Although we certainly subscrive to the principle that the child's own esophagus is best and that the esophagus can be preserved in a majority of cases, we believe that, in some cases, this is impossibile. (10)

The usual indications for esophageal replacement in childood are intractable strictures and long gap atresia.(3) In our first case the esophageal replacement was necessary because there was a big gap between the esophageal stumps. In the second child, his entire infancy was dominated by endless attempts to preserve the native esophagus at all costs but his esophagus didn't function normally.

When bridging esophageal defects, there is a difference between the difficulty of the operation and a long-term results to achieve. Type and location of the graft depend on etiology and surgeon preferences, even if none fully replicates the features of a normal esophagus. Several options are now available with good results, such as replacement with colon, stomach or jejunum. (11) Gastric transposition is one of the easy procedures, followed by colonic interposition and by jejunal graft interposition. Free jejunal graft interposition with microvascular anastomoses would be the most demanding one.(12)

The vast majority of adult patients show good swallowing function after free jejunal graft following cervical pharyngoesophagectomy for cancer. $(13 ; 14)$ This is certainly related to the fact that jejunum retains peristaltic activity. Preservation of peristaltic activity was described for free jejunal grafts as well as for pedicle grafts. A peristltic activity of jejunum is highly desiderable for normal transit and minimisation of stasis and reflux, even though this activity is slower than that of the esophagus. (15) Our first patient is a little boy and we can gain enough jejunal lenght on its pedicle with a good blood supply. Therefore, we can use jejunum that doesn't dilate and retains good peristalsis. The jejunum has a diameter similar to the esophagus and therefore it occupies less space within the thoracic cavity than the stomach. This is partcurarly important when pulmonary considerations are taken into account. Esophageal replacement with jejunum is a demanding operation with considerable morbidity, but in our patient there weren't complications. The other boy is 6 years old and he had herniation of gastric fundic in the chest. We therefore decided to refer the patient to gastric transposition. This is the simplest technical procedure of esophageal replacement in children, with satisfactory results. The excellent blood supply of the stomach only one anastomosis are clear advantages of this tecnique. Mortality rate of 5,2\% is described by Spitz. $(10 ; 16)$ Our patient after the operation can swallow normally and he has good growth. It is important to perform a formal pyloroplasty to prevent a delayed gastric emptying. $(17 ; 18)$

Some surgeons use colon for esophageal replacement. In contrast to jejunum peristalsis in the colon is usually absent and transit is assisted by gravity. $(17 ; 19 ; 20)$

In our two cases we traspose jejunum and stomach between posterior mediastinum. Our preferred approach is to use the posterior mediastinum route, developed by blunt dissection from below via the hiatus and from above through the cervical incision. In this tecnique there is a phase where blind finger dissection is necessary. The guide for this phase of dissection is the spine, and the surgeon's fingers should re- main in contact with the vertebra. (1) This maneuver was accomplished without difficultiy in the first case. In the second case we had some difficulty because he was undergone many surgeries before.

\section{CONCLUSION}

When the native and diseased esophagus should be removed we must submit a patient to esophageal replacement.

Esophageal replacement is a complex surgical procedure, which provides various options. Only a careful preoperative evaluation allows us a choice of organ to be used as esophageal substitute. The colon is the most widely used. There are other surgical options that may offer, in skilled hands, the same guarantees. Both our cases have a good long term follow-up with regular diet and weight-height growth. Our experience confirms the validity of the 2 techniques, which include preferably the use of posterior mediastinal way and careful surgical preparation of the bowels.

\section{REFERENCES}

1.L. Spitz, E. Kiely, A. Pierro "Gastric transposition in children: a 21 year experience" Journal of Pediatric Surgery, 39 (3): 276$281 ; 2004$.

2.N.M.A. Bax, D.C. Van der Zee "Jejunal pedicle grafts for reconstruction of the esophagus in children" Journal of Pediatric Surgery, 42: 363-369; 2007.

3.G.R. Arul, D. Parikh "Oesophageal replacement in children" Ann R Coll Surg Engl 90:7-12; 2008

4.V. Czerny "Neue Operationem" Zentralblatt Chir 4: 443; 1877 5.RE. Gross "The surgery of infancy and childood" Philadelphia, PA: W.B. Saunders, 1953

6.SS.Yudin "The surgical construction of 80 cases of artificial esophagus" Surg Gynaecol Obstet 1944; 78: 561.

7.D. Gavriliu "Replacement of the esophagus by a reverse gastric tube" Curr Problems Surg 1975; 12: 36-64.

8.RH. Sweet "Subtotal esophagectomy with high intrathoracic esophago-gastric anasto-mosis in the treatment of extensive cicatricial obliteration of esophagus" Surg Gynaecol Obstet 1947; 83: 417.

9.W.A. Dale, C.D. Sherman "Late reconstruction of congenital oesophageal atresia by intrathoracic colon transplantation" J Thorac Cardiovasc Surg 1955; 29: 344.

10.L. Spitz, "Gastric transposition in children" Journal of Pediatric Surgery, 18: 30-33; 2009.

11.Prema Menon and K.L.N. Rao "Esophageal surgery in newborns, infants and children" Indian Journal of Pediatrics, 75: 939-943; 2008

12.N.M.A. Bax, "Jejunum for bridging long-gap esophageal atresia" Journal of Pediatric Surgery, 18: 34-39; 2009.

13.G.C. Oniscu, $R$ Sanderson "Functional results following pharyngolaryngoesophagectomy with free jejunal graft reconstruction" Eur J Cardiovasc Surg 2001; 19: 406-410

14.Y Shirakara, Y Naomoto et al. "Free jejunal graft for hypopharyngeal and esophageal reconstructio" Langenbecks Arch Surg 2004; 389: 287-390

15.J.A. Cauchi, R.G. Buick, D.H. Parikh et al. "Oesophageal substitution with free and pedicled jejunum: short- and long-term outcomes" Pediatr Surg Int 23: 11-19; 2007

16.R.B. Hirschi, A.G. Coran et al. "Gastric transposition for esophageal replacement in children: experience with 41 consecutive cases with special emphasis on esophageal atresia" Annals of Surgery 236 (4): 531-541; 2002

17.U. Tannuri et al. "Which is better for esophageal substitution in children, esogocoloplasty or gastric transposition? A 27-year experience of a single center" Journal of Pediatric Surgery 42, 500-504; 2007

18.L. Ludman, L. Spitz "Quality of life after gastric transposition for oesophageal atresia" Journal of Pediatric Surgery 38, 53-57; 2003

19.K.D. Gupta, S Sharma "Esophageal atresia: the total care in a high-risk population" Seminars in Pediatric surgery 17, 236$243 ; 2008$

20.A.F. Hamza, "Colonic replacement in cases of esophageal atresia" Seminars in Pediatric Surgery 18: 40-43; 2009 